\title{
SYNOPSIS OF STUDIES ON SYTHETIC FUELS \\ PRODUCTION BY FUSION REACTORS
}

\section{J. Powe 11}

\section{Introduction}

This is a synopsis of a BNL report entitled "An Evaluation of the Technical, Economic,' and Environmental Features of a Synthetic Fuels Energy Sygtem Based on Fusion Reactors" by $\mathrm{J}$. Powell, F. Salzano, w. Sevian, K. Hoffman and D. Bezler, which is. in preparation and should be issued in a few weeks. The possibility of using electricity, radiation (UV or other), and/or heat from fusion reactors to produce synthetic fuels has been previously suggested by a number of authors, including W. Gough, B. Eastlund, R. Huse, and E. Tanner, among others.

In this study we examine in detail the impact of synthetic fuels produced by fusion reactors on the resource consumption of the United States for the reference year 2020; the effect on the environment, including thermal and chemical emissions, and the economic perturbations induced by the eynthetic fuel production. We examine several energy systems for 2020 with different degrees of synthetic fuel utilization. A prims objective of this study is thus to assess the advantages and disadvantages of synthetic fuel production by fusion reactors.

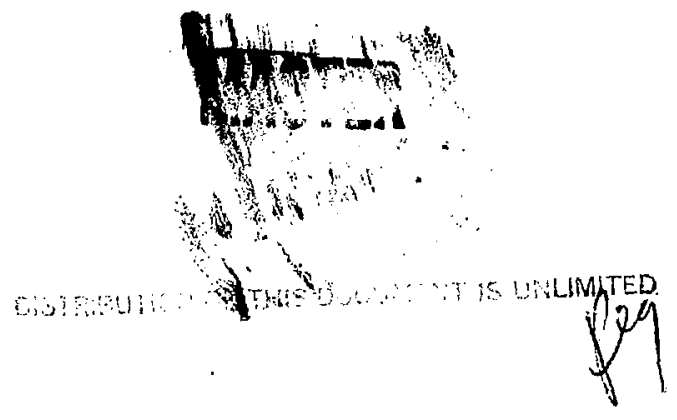


A further objective of this study is to determine the optimum CTR reactor design for synthetic fuel production. To do this we examine the effects of CTR reactor type, nature of the fuel cycle, MW(e) rating, firgt wall flux, and plasma containment parameters. We attempt by means of a detailed cost analysis, as far as is possible with the inherent unknowns, to determine how synthetic fuel costs will be affected by these variables.

The environmental problems of siting large fusion reactors are also examined.

\section{Energy Systems Analygis}

Four energy systems for the U.S. in 2020 A.D. are compared. The reference energy systemg (gystem A) was developed in a previous BNL study. This system does not assume any fusion power input: the only inputs are LWR, LMFBR, hydropower, coal, oil, and gas. This reference energy system is constructed by projecting demands for a large number of end uses le.g., auto transport, home heating, primary metal processing, etc.), and then determining what inputs are necessary to meet the deaands, using appropriate efficiencies for each stage of energy production, transmissions, distributions, and final use.

The projectiong of energy demand involve a large number of factors, including expected increases in population, changes in 
houschold size, growth rate predictions for various industries, transportation modes , etc.

Three perturbed energy aystems are then derived from the reference energy system (oygtem A) corresponding to different degrees of penetration by fusion reactors. In. gystem B, 50\% of the nuclear electric power is supplied by fusion reactors, with the remaindex by LWR'g and LMFBR's. No synthetic fuel production from nuclear electric sources is assumed. In systen c, all of the nuclear electric power is supplied by fusion reactors. In addition, sufficient synthetic fuel is produced by fusion reactors to eliminate all imports of oil and gas, as well as the elimination of all strip mining and coal gasification. In system D, all of the nuclear electric power is supplied by fusion reactors, and synthetic fuel takes over all markets that it is technically capable of supplying. Those markets which cannot be supplied by synthetic fuels without major changes in processing or use patterns continue to be supplied by fossil fuels. In system $D$ this principally comprises the petrochemical and steel indugtries.

The changes in resource consumption, environmental emissions, and cost for each of the three perturbed sygtems are then evaluated.

Several important results emerge from this study: 
1. The synthetic fuels that can be readily produced by fugion reactors $\left(\mathrm{H}_{2}\right.$ gas, methanol, and liquid $\left.\mathrm{H}_{2}\right)$ can supply moat of the demand categories that would be normally supplied by fossil fuels. In system $D$, for example, the total fossil fuel demand is reduced to $13 \%$ of the demand in system $A$.

2. The total energy release (all forms of energy) to the environment is increased from $300 \times 10^{15}$ Btu (system A) to $540 \times 10^{15}$ Btu (system D) if one goes to a nearly complete synthetic fuel economy. This increase seems acceptable, particularly if the fusion reactors discharge their waste heat in offshore cóastal waters.

3. If fusion reactors are used for production of synthetic fuels, the total amount of CTR generation will be much larger. The total CTR electric generation in system B is $21 \times 10^{15}$ Btu/ year (no synthetic fuel production): in system D the total CTR electric generation is $205 \times 10^{15}$ Btu/year (synthetic fuels based on $\mathrm{H}_{2}$ gas produced by water electrolysis). This ten fold increase in CTR electric generation has very important implications for CTR technology. The unit rating of CTR reactors can then be much larger than would be practical if no synthetic fuels are produced. Further, with synthetic fuels production, load variations are much smaller than those for conventional electric generation. permitting all planto to be base laaded; in addition, the transmission cost of synthetic fuels is substantially below 
that of electricity, permitting generating sites to be further away from load centerg. Thus CTR reactor unit ratings of 10,000 to 20.000 MW(e) are practical for synthetic fuel production. Unit ratings would have to be much smaller, in the order of 1000-2000 MW(e), if synthetic fuels are not produced. The much larger .CTR unit ratings for systems $C$ and $D$ appear to significantly reduce reactor cost in $\$ / k w(e)$ and to make plasma containment simpler.

4. Environmental emissions, $\mathrm{Co}, \mathrm{No}_{\mathrm{x}}$, etc., are an order of magnitude lower for systems $C$ and $D$. The radioactive waste emissions and inventories essentially go to zero. In addition, the elimination of strip mining for coal and the large reduction of underground coal mining that is possible with systems $C$ and $D$ will reduce water pollution and land spoilage.

5. Systems C and D are much: cloger together than are systems B and $C$. This indicates that a decision to eliminate oil and gas imports and not use coal gasification in $2020 \mathrm{AD}$ could lead to virtually a complete synthetic fuels energy system.

Synthetic Fuels: Choises, Production Methods, and Economics

A synthetic fuel energy system based on, $\mathrm{H}_{2}$ has a number of important features:

a) The onergy system does not depend on depletable resources.

b) $\mathrm{H}_{2}$ based fuels have good substitutability for presently used fuels. 
c) The amount of fixed carbon that is required is minimized.

d) Environmental emissions are minimized.

$H_{2}$ gas can be substituted for natural gas in residential and commercial space heating, as well as industrial process heating. The safety problems with $\mathrm{H}_{2}$ gas should be comparable to those with natural gas, and if it can be transported in presently existing natural gas pipelines, only compressors would have to. be replaced

Methanol, derived from $\mathrm{CO}_{2}$ and $\mathrm{H}_{2}$, can be used as a portable ruel for internal combustion engines in autos, buses, trucks, and trains. The energy content per gallon is approximately one-half that of gasoline, but it gives good motor performance and lower emissions than gasoline.

Liquid $\mathrm{H}_{2}$ can be used as a fuel for jet airplanes. NASA tests indicate it should be feasible to adapt jets to liquid hydrogen, and airplane performance should improve. payload or range should be increased by $20-30 \%$.

There are other possible fuel choices, but in general they do not appear as practical, cost significantly more, or require more work to prove their feasibility.

The present methods of methanol synthesis and $\mathrm{H}_{2}$ liquefaction are well developed and routinely used on an industrial scale. of the three possible methods for $\mathrm{H}_{2}$ production from water, 
(electrolysis, thermal dissociation and photolysis), only electrolysis has been deyeloped for use on an indugtrial scalc. Present electrolysis cells are normally operable at $-60-130 \%$. efficiency, depending on power cost, cell cost, etc. Recent developments indicate that electrolysis cell costs can be as low as $\sim \$ 45 / \mathrm{KW}\left[\mathrm{H}_{2}\right.$ output]at $70 \%$ efficiency for installations of several hundred $k w(e)$. Multi-gigawatt installations would be necessary for synthetic fuel production. We anticipate that on this scale it should be possible to operate at $80 \%$ efficiency with cell costs of $\$ 35 / K W(e)$ (input, not including power supply). Thé thermal cycle efficiency (heat to electricity) for CTR reactors is taken as $40 \%$, comparable to present fossil fueled plants. A cell efficiency of $80 \%$ then yields an overall $\mathrm{H}_{2}$ production efficiency of $32 \%$ (heat to $\mathrm{H}_{2}$ chemical energy). This overall efficiency is $\sim 50 \%$ of carnot at a heat source temperature of $500^{\circ} \mathrm{C}$.

The various multi-step chemical dissociation cycles that have been proposed by de Beni and Marchetti all require maximum temperatures of $750^{\circ} \mathrm{C}$ or above. Predictions of overall cycle efficiencies (heat to $\mathrm{H}_{2}$ chemical energy) are claimed to be on the oxder of 50\%. However, no measurements of overall efficiency for a practical process have been made. similarly, the economics of thermal dissociation cycles are not known. If a multi-step thermal dissociation cycle is to compete with water 
electrolysis it must have good heat economy and low capital cost. More work is neccasary to delermine whether or not thermal diagociation eycles can compete with olectrolysis. It should also be noted that any potential savings over electrolysis could be easily eaten up if the higher blanket temperatures that wịll be necessary significantly increase blanket cost.

The photolysis of water vapor using UV from the hot plasma is an attractive possibility. However, if it would have to be used in conjunction with an electrolyalo plant, since the overall efficiency for the production by photolysis alone is too small for it to compete with electrolysis. The conibined overall efficiency (heat to $\mathrm{H}_{2}$ chemical energy) could then be significantly greater than that for pure electrolysis. However. more detailed analytical and experimental studies are necessary to determine whether the combined cycle is practical.

The analysia assuming only electrolytic production thus scts an upper limit to $\mathrm{H}_{2}$ production costs. Thermal dissociation or UV photolysis may lower these costs somewhat, though this is far from certain. However, as it turns out, the costs are low enough with electrolysis that synthetic fuel production based on CTR reactors is economically practical. Environmental factors could then tend to favor use of CTR's for symthetic fuel production rather than coal gasification. 
The estimates of CTR reactor plant cost lincluding electroIyzer and non-nuclear components) range from $\$ 200$ to $\$ 300 / \mathrm{kW}(\mathrm{c})$. dep̣ending on reactor parameters. These cost estimates are described in more detail in a later section. The production costs for $\mathrm{H}_{2}$ gas range from $\$ 1.77$ to $2.55 / 10^{6}$. Btu, depending on CTR reactor cost. This assumes $80 \%$ load factor, $80 \%$ efficiency for electrolyzers, 15\% capital charges (depreciation, interest charges, taxes. etc.), and $O$ and $M$ costs of $\$ 0.20 / 10^{6}$ Btu. These production costs are somewhat higher than the projected production cost of natural gas in $2000 \mathrm{AD}$ of $\$ 0.90 / 10^{6}$ Btu (well head price in 1970 dollars) and the projected production cost of $\$ 1.25 / 10^{6}$ Btu for synthetic gas from coal $[2000 \mathrm{AD}$ cost in 1970 dollars]. However, natural gas will be much scarcer after 2020 and the price in 1970 dollars can be expected to be considerably higher. Sufficient coal exists to keep the price of synthetic gas from coal relatively stable for a long time, but large scale use for long periods of time will cause severe environmental strain unless strict controls are applied.

Fusion reactors could produce $\mathrm{H}_{2}$ as cheaply as gas from coal if cost and efficiency improvements axe made. For example, if electrolyzer efficiency and load factor are both increased to 90\%, and capital cost decreases to $\$ 150 / \mathrm{kW}$ (e) [ through less expensive construction and/or increases in thermal efficiency] then $H_{2}$ production costs are reduced to $\$ 1.13 / 10^{6}$ Btu. 
The transmission and distribution costs to the various markets must be added to these production costs. These will be relatively small for industrial users and of the order of production costs for residential users. as is the present problem. - The projected refinery price for gasoline in 2000 AD is \$0.38fgallon (1970 dollars) and the price in 2020 should be substantially higher. Production costs for methanol range from 0.20 to $\$ 0.25 /$ gallon for $H_{2}$ production costs of $\$ 1.77$ to $\$ 2.55 / 10^{6}$ Btu. However, the fuel value of methanol is only $50 \%$ that of gasoline [per gallon], so that the above methanol costs should be doubled when compaxing with gasoline. Thus methanol can compete very favorably with gaso:ine for auto, bus, and truck transport.

The projected refinery price for kerosing jet fuel in 2000 AD is $\$ 0.36 / 9 a 110$ [ [1970 dollars] which is equivalent to $\$ 3.17 / 10^{6}$ Btu. The 2020 price should be substantially higher. The production cost for liquid $\mathrm{H}_{2}$ for airplanes is estimated to range from $\$ 2.71$ to $\$ 3.88 / 10^{6}$ Btu for $H_{2}$ production costs of $\$ 1.77$ to $\$ 2.55 / 10^{6}$ Btu, so liquid $H_{2}$ should successfully compete with jet fuel. Furthermore, increases of approximately $30 \%$ in payload or range are estimated. with liquid $\mathrm{H}_{2}$ fuel over that obtainable with subsonic jets operating on conventional jet fuel. This advantage would make liquid $\mathrm{H}_{2}$ the preferred fuel for air transport. 
No credit has been taken in these cost projections for the $\mathrm{O}_{2}$ produced by water electrolysis. However, it is unlikely that the enormous amount of $\mathrm{O}_{2}$ produced in a synthetic fuel economy could be marketed at current prices. There will un-doubtedly be some value to the $\mathrm{O}_{2}$. which will reduce the cost of the synthetic fuel, but further studieg are required to determine the amount. If all the $o_{.2}$ could be marketed at current prices, the cost of synthetic fuel would be essentialiy zero. CTR Reactors: Choices and costs

We concentrated on one reactor type, the tokamak, and investigated the effect of various reactor parameters in detail, rather than attempting a less detailed comparison of a number of CTR reactor types. This primarily reflects the more advanced state of tokamak research, as well as the smaller number of technological unknowns. This is not meant to imply that other CTR reactor types might not be suitable.

The much larger reactor rating that is practical if synthetic fuels are produced has a number of important implications for CTR reactor design. At $10,000 \mathrm{MW}(e)$, for example, a $\theta$ pinch reactor would have a total length of approximately $5 \mathrm{~km}$, permitting one to use a linear pinch instead of a toroidal one. Problems of stability would thus be eased. The practicality of siting a $5 \mathrm{Km}$ long reactor plant would have to be examined, however. Similarly, a long reactor with multiple mirrors might be more feastble with very large ratings. Stellaratorg would 
also benefit by large power ratings aince agpect ratios and plasma diameters could then be Increased. Both would help to reduce unit magnet costs.

The effects of the following parameters are investigated for tokamaks: .
a) Fuel cycle (catalyzed DD and DT)
b) Reactor rating $(5000,10,000$ and 20,000 MW(e))
c) First wall Elux $\left(1,2\right.$, and $\left.4 \mathrm{Mw}(\mathrm{th}) / \mathrm{m}^{2}\right)$
a) Plasma containment parameters

$$
\begin{aligned}
& \text { (i) "nominal" }-q=2.0, \theta_{\theta}=2.5, A=3.75 \\
& \text { (ii) "optimistic" }-q=1.4, \theta_{\theta}=3.0, A=3.75 \\
& \text { (iii) "pessimistic" }-q=3.0, B_{\theta}=2.0, A=3.75
\end{aligned}
$$

Appropriate reactor and magnet designs for each parametric combination are developed. All magnets are of the warm reinforcement type in which magnetic forces on the superconductor are carried direckly to room temperature' through a low thermal conductivity, high strength barrier of epoxy fiberglass and stainless steel sheets. This type of construction is much

" cheaper for the very large magnets that are required, since the cost of the added refrigeration load is only a gmall fraction of the savings in magnet structure cost. For tokamaks, the magnet warm reinforcement atructure is aimply the pulser steel that starts the plasma ring current. 
- For the designs considered, the amount of pulser steel is deteru...ned by a set of -conditions:

a) That $A B_{v}$ in the steel be $4.0 \mathrm{~T}(+2$ to -2 swing)

b) That sufficient flux be available to

(i) ohmically. heat the plasma to $\sim 1 \mathrm{keV}$

- (ii) establish the ring current for plasma equilibrium

(iii) maintain the ring current against IR drop for several hours

Given these constrainta, the amount of pulser steel is then determined for each case. This in turn determines the structuräl stresses resulting from the magnetic forces. These structural stresses (computed by 2 dimensional finite element codes) vary from cases to case, depending on the choice of parameters (plasma size, containment parameters, etc.). The maximun stress in the structure ranges between $\sim 5 \mathrm{KsI}$ to $\sim 20 \mathrm{Kgi}$ for the various cases investigated, well within the allowable Iimit.

In a few cases there is insufficient throat area to carry the required flux if $A B$, is 2 imited to $4.0 \mathrm{~T}$. These occur for catalyzed DD fuel cycles at high wall fluxes with pessimistic plasma containment parameters. The coat of energy storage for an air core transformer would be prohibitive so these cases are not considered feagible. 
In oll designs the plasma ring current is established by transformex action. Diffusion current driven tokamaks are an interesting possibility, but are more of an extrapolation. If feagible, they could subgtantially reduce sagnet cost, since most of its cost is due to the pulser steel. The catalyzed DD reactors start on lower density DR fuel and then shift to the DD cycle on a time scale of several minutes. Pulse times for the DD reactors are $\sim 24$ hours, so startup is a minor part of the operating cycle. The plasma ring current increases during the shift from DT to DD fuel go as to maintain plasma equilibrium, though constant power dengity is maintained during the shift. Most of the inductive energy associated with the final value of plasma ring current is supplied on a slow time scale (minutes) from the reactor output so that energy storage requirements are minimized.

The ohmic heating phase initially heats the DT fuel to $\sim$ Kev. DT ignition is then reached with neutral beam heating. The fueling is assumed to be provided by pellet injection. For the catalyzed DD cases this will involve infecting primarily $D$ with some $\mathrm{He}^{3}$ and $\mathrm{T}$.

Startup of the DT reactors is similar except that there is no shift to DD fuel. Because of the lower plasma electrical conductivity for DT reactors (a result of the lower operating 
temperatures), the pulge times will be shorter than those for DD reactors, and will be on the order of several hours.

Reactor power balances are also computed. Because of the large physical dimensions of these reactors, confinement problems are considerably eased for the largest sizes invegtigated, for example, the plasma lifetime could be as low as 30 Bohm times and the reactor would st.ill operate.

Reactor plant costs are divided into three categories: nonnuclear components (site improvements, gtructures, steam supply (except CTR blanket), turbine-generator, miscellaneous yard and electrical equipment, etc): CTR reactor components (maynets, structure, cryogenic, blanket, and plasma heating and refueiing): and electrolyzer components (cells, gas storage, etc.). Cost estimates for each installed component are then made, including materials and labor, in 1970 dollars. Site costs are not included. Undistributed coots of $19 \%$ of direct material and labor costs are added for design, etc. Interest during construction of $25 \%$ of total direct costs is also added. No escalation is included since the production costs of synthetic fuels from CTR reactors are compareà against fuel costs projected to 2020 in 1970 dollars.

The non-nuclear component costs are obtained from the Middletown study prepared for the AEC using scaling factors 
supplied by ORNL. The turbine generator unit rating is taken as $2500 \mathrm{~m}(\mathrm{e})$ : multiple unitg are required for the $5000,10,000$, and $20,000 \mathrm{MW}(\mathrm{e})$ plants lnvestigated in this study. All other account unit costs are scaled only to $5000 \mathrm{MW}(\mathrm{e})$ and assumed constant for larger plant sizes, except for the structure and improvements account. Unit costs for this account were scaled to $5000,10,000$ and $20,000 \mathrm{MW}(\mathrm{e})$.

The turbine generator costs assume $60 \mathrm{H}_{\mathrm{z}}$ output: in actu- ality, cheaper acyclic generators would be used to supply the electrolysis units. GE estimates only about $\$ 8 / \mathrm{KW}(\mathrm{e})$ for acyclic generators. Thus the turbine generatior costs in this study are probably somewhat higher than would be the case.

The total direct costs (including undistributed costs) for the non-nuclear components range from $\$ 94 / K W(e)$ for 5000 IW (e) plants to $\$ 99 / \mathrm{KW}(\mathrm{e})$ for $20,000 \mathrm{MW}(\mathrm{e})$ plants.

CTR reactor costa are obtained by estimating the cost of the fabricated materials for the various reactor components (magnet structure, cryogenic system, blanket, etc.) and adding an appropriate fraction (e.g., 50\%) for installation. Unaistributed costs are assumed to be $20 \%$ of direct materials and labor casts.

Superconductor costs are obtained from an earlier BNL study on the projected costs of superconductors in a fugion 
power economy: Neutral beam heating costs are taken from a LLL study on mirror reactors.

The CTR reactor total direct costs (including undistributed costs) range from $\$ 40$ to $\$ 110 / \mathrm{KW}(e)$. They are smaller for $\mathrm{DT}$

"cycles with high wall loadings and greatest for catalyzed DD cycles with low wall loadings.

The electrolysis cell costs are taken as $\$ 35 / \mathrm{KW}(\mathrm{e})$ of input at $80 \%$ efficiency. This includes all necessary auxiliaries, buildings, etc., but not the power supply, which is included in the turbine-generator cost. Teledyne estimates that electrolysis cells can now be built for $\$ 45 / \mathrm{kW}(\mathrm{e})$ of input at $70 \%$ efficiency, for installations of geveral hundred $k w(e)$. The projected cogt of $\$ 35 / \mathrm{kW}(\mathrm{e})$ may well be too high considering that installations involving thousands of MW(e) would be necessary for a synthetic fuel plant. The very much larger scale should great.ly reduce costs.

The total plant costs, counting all material and labor costs , undistributed costs and interest during construction range from $\sim \$ 200$ to $\sim \$ 300 / \mathrm{KW}(e)$, depending on reactor parameters. Several important conclusions emerge from this portion of the study:

1. Catalyzed DD and DT fuel cycles result in essentially the same reactor plant cost. Thus if tritium breeding blankets 
are not technologically feasible, or involve excessive hazard, - it-should be possible to uge the DD cycle. It probably would not be practical to use the DD cycle for the smaller reactor ratings (e.g., $1000 \mathrm{MW}(e)$ appropriate to reactors used only for electric generation.

- 2. The reactor plant rating does not significantly decrease plant cost/KW(e) in the range of 5000 to $20,000 \mathrm{MW}(\mathrm{e})$. This is a result of the assumption that most of the unit costs for both the non-nuclear and the reactor components, do not decrease for plant sizes greater than 5000 MW(e). This may be too conservative.

3. The first wall flux does significantly affect plant cost $/ \mathrm{kW}(\mathrm{e})$ in the range of 1 to $4 \mathrm{MW}(\mathrm{th}) / \mathrm{m}^{2}$, with unit plant costs approximately $20 \%$ lower at $4 \mathrm{MW}(\mathrm{th}) / \mathrm{m}^{2}$ than those at 1 . MW $(t h) / m^{2}$. It thus appears that high wall fluxes. while important in reducing plant costs, are not imperative to an economically practical reactor plant.

4. Plasma containment parameters do not gignificantly - affect unit plant costa for the range atudied $\left(q-1.4, b_{\Theta}=3\right.$ to $\left.q=3.0, B_{\Theta}=3.0\right)$. This results from the warm reinforcement magnet approach in which the amount of structural steel is determined by flux change requirements for the tokamak, instead of atructural stresg. The flux change requirements are only gecondarily affected by the plasma containment parameters. 
Poor plasma containment parametera increase superconductor cost, but this is a small part of the total plant cost. Poor containment also increages the magnet gtructural stress, but. this remains within allowable limits. The containment parameters principally affect the type of superconductor required. DT reactors can be built using NbTi superconductor with optimistic and nominal containment parameters, but require $\mathrm{Nb}_{3} \mathrm{sn}$ with pessimistic containment parameters. DD reactors can use MoTi with optimistic containment, but require $\mathrm{Nb}_{3} \mathrm{Sn}$ with nominal containment, and would probably not be technically feasible $\left(B_{\max } \approx 25 \mathrm{~T}\right)$ with pessimistic containment.

\section{Siting of CTR Plants}

The total CrR electric generating capacity in system $D$ is $8.5 \times 10^{6} \mathrm{MW}(\mathrm{e})$ (80\% load factor). This would require 850 $10,000 \mathrm{MW}(\mathrm{e})$ plants, for example. with a total thermal discharge of $1.3^{1} \times 10^{7} \mathrm{MW}(\mathrm{th})$ from the plants. The individual plants mày pose siting problems in some instances but it is doubtful that serious effects on continental us climate would arise, since the total thermal discharge power for the Us would only be on the order of $1 \%$ of the average solar power received by the continental us.

These large plants would most likely be situated along the us east and west coasts, with deep water fe.g. 250 feet or 
greater) thermal discharge. Plants could be located either off-shore or on coasts with pipelines for deep water discharye: Analyses by General Dynamics of the environmental effects of deep water thermal discharges from off-shore submerged fiogion power plants indicate that mixing is rapid and the surface. temperature rise is smaller than $1^{\circ} \mathrm{F}$. Their studies further indicate that there is no significant effect on biologic populations in the vicinity of these thermal discharges. No serious problems seem to arise with regard to the transmission of synthetic fuels from production sites on the east and west coasts. It probably will be necessary to construct $\mathrm{H}_{2}$ liquefaction plants for aircraft fuel near the point of use, but $\mathrm{H}_{2}$ gas can be transported via pipeline to such points.

\section{Summary and Conclusions}

The principal conclusions of this study are:

1) Synthetic fuels derived from fusion reactors can supply most of the U.S. energy needs, eliminating all oil and gas imports, coal gasification, and coal strip mining. Fusion reactors can supply these synthetic fuels indefinitely into the future.

2) Synthetic fuel from fusion reactorg will probably be somewhat more expensive than synthetlc fuels derived from coal. 
However. the use of fusion reactors would avoid having to strip mine a large fraction of the west. Without fusion reactors $\leadsto 000 \mathrm{mi}^{2} /$ year would have to be stripped. Further, conservative fusion reactor and $H_{2}$ production technology has been assumed for this analygis, and it is possible that synthetic fuel production costs may be significantly less than those we have projected.

3) Fusion reactors seem preferabíe to fission reactors for the production of synthetic fuels. Synthetic fuel production costs are somewhat lower with fusion reactors, but more importantly, the radioactive waste problem is virtually eliminated.

4) CTR power generation in the U.S. is almost an order of magnitude larger if CTR's are used for oynthetic fuel production rather than only for electric generation.

5) CTR unit reactor size can be much larger if synthetic fuels are produced. Unit ratings on the order of $20,000 \mathrm{MW}(\mathrm{e})$ appear compatible with the total v.s. energy system. If CrR's are used only for electric generation, the unit ratings will have to be approximately an order of magnitude lower. In addition. synthetic fuel CTR plants can be all base loaded, where some electric generation plants cannot be base loaded.

6) Catalyzed DD fuel cycles appear competitive with DT fuel cycles for large power ratings. A DD cycle ohould greatly 
ease blanket development problems, and could result in much cheaper blankets. It should also greatly reduce tritium amissons and inventories from the amounts in a DT cycle.

7) The large reactor ratings possible with synthetic fuel production should significantly ease plasma containment problems. Because of the large plasma diameter, the ratio of required containment time/Bohm time is much smaller than the value necessary for reactors used only for electric generation. Also, weaker magnetic fields can be used for containment.

$-22-$ 